"This is the peer reviewed version of the following article: Angew. Chem. Int. Ed. 2016, 11207-11211 which has been published in

final form at http://onlinelibrary.wiley.com/doi/10.1002/anie.201605162/abstract]. This article may be used for noncommercial purposes in accordance with Wiley Terms and Conditions for Self-Archiving."

\title{
Ni-Catalyzed Reductive Amidation of Unactivated Alkyl Bromides
}

\author{
Eloisa Serrano, ${ }^{[a]}$ Ruben Martin*[a],[b]
}

\begin{abstract}
A user-friendly Ni-catalyzed reductive amidation of unactivated primary, secondary and tertiary alkyl bromides with isocyanates is described. This catalytic strategy offers an efficient synthesis of a wide range of aliphatic amides under mild conditions and with an excellent chemoselectivity profile while avoiding the use of stoichiometric and sensitive organometallic reagents.
\end{abstract}

Although unactivated alkyl halides are inherently disposed towards destructive $\beta$-hydride elimination and homodimerization pathways, these counterparts have successfully been employed in a myriad of metal-catalyzed cross-coupling reactions. ${ }^{[1]}$ At present, the vast majority of these processes are based on stoichiometric, well-defined, and in many instances, air-sensitive organometallic species. Challenged by these drawbacks, the recent years have witnessed the development of crosselectrophile coupling processes, ${ }^{[2]}$ becoming powerful and practical synthetic alternatives to classical cross-coupling reactions, achieving an otherwise similar molecular complexity under milder reaction conditions while avoiding the need for organometallic reagents.

Despite the advances realized, the palette of electrophilic partners in cross-electrophile processes remains rather limited when compared with classical nucleophile/electrophile regimes. It comes as a surprise that isocyanates, privileged synthons in industrial settings ${ }^{[3]}$ have been virtually unexplored in crosselectrophile events with organic (pseudo)halides. ${ }^{[4,5]}$ This is likely due to the strong binding properties of isocyanates to low valent transition metal complexes, leading to unproductive dimerization or trimerization pathways. ${ }^{[6]}$ At present, cross-electrophile coupling reactions with isocyanates as coupling partners remain confined to substrates that rapidly undergo oxidative addition such as aryl or benzyl halides lacking $\beta$-hydrogens, thus preventing undesired pathways (Scheme 1 , path a). ${ }^{[7]}$ Ideally, this field of expertise should include the use of unactivated alkyl halides possessing $\beta$-hydrogens, ${ }^{[1]}$ thus resulting in a new synthetic route for rapidly preparing aliphatic amides, ubiquitous motifs in pharmaceuticals, agrochemicals, peptides and polymers ${ }^{[8]}$ Indeed, a close look into the literature data indicates that there is a paucity of highly chemoselective catalytic $C-C$ bond-forming processes ${ }^{[9]}$ with improved flexibility, practicality and generality that would give access to primary, secondary or

[a] E. Serrano, Prof. R. Martin

Institute of Chemical Research of Catalonia (ICIQ)

The Barcelona Institute of Science and Technology

Av. Països Catalans 16, 43007, Tarragona (Spain)

E-mail: rmartinromo@iciq.es

[b] Prof. R. Martin

Catalan Institution for Research and Advanced Studies (ICREA)

Passeig Lluïs Companys, 23, 08010, Barcelona (Spain)

Supporting information for this article is given via a link at the end of the document.((Please delete this text if not appropriate)) even tertiary amides at will, including hindered substrate combinations, while avoiding the handling of carbon monoxide (CO) at high pressures ${ }^{[10]}$ or well-defined and stoichiometric organometallic species, ${ }^{[11]}$ among others (Scheme 1, path b) ${ }^{[12]}$

As part of our interest in reductive coupling reactions, ${ }^{[13]}$ we questioned whether a unified catalytic umpolung strategy via the in situ generation of carbogenic nucleophiles (II) from unactivated alkyl halides (I) and their coupling with isocyanates would constitute a generic platform for preparing aliphatic amides (III) (Scheme 1, bottom). However, at the outset of our investigations it was unclear whether it would be possible to balance the high reactivity of isocyanates and the commonly observed parasitic $\beta$-hydride elimination or homodimerization pathways when using unactivated alkyl halides. Herein, we describe the successful realization of this concept, providing access to primary, secondary, and even tertiary alkyl amides by exploiting a previously unrecognized opportunity via sequential cross-coupling reactions of three different electrophiles.

Catalytic reductive amidation using activated substrates

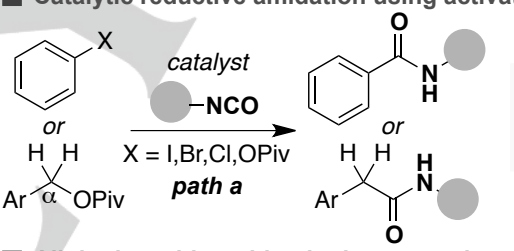

Lack of $\beta$-hydrogens

- Restricted to ArX \& BnX (fast oxidative addition)

Aliphatic amides with $\beta$-hydrogens using organometallic specie

B广 $\delta^{-} M$

$$
\underset{\text { path } \vec{b}}{-\mathrm{NCO}} \underbrace{\mathrm{s}^{5}}_{\mathrm{H}}
$$

Well-defined R-M species

$\mathrm{M}=\mathrm{Li}, \mathrm{MgX}$

This work: catalytic reductive amidation of unactivated alkyl bromides

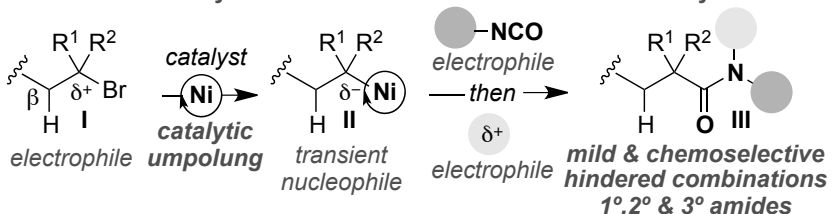

Scheme 1. Amide synthesis via $\mathrm{C}-\mathrm{C}$ bond-formation using isocyanates

We began our investigations by studying the reaction of $\mathbf{1 a}$ with isocyanate $\mathbf{2 a}$ (Scheme 2). The choice of $\mathbf{2 a}$ was not arbitrary, as primary amides can be prepared by simple deprotection of the tert-butyl group. ${ }^{[14]}$ After judicious evaluation of the reaction parameters, ${ }^{[15]}$ we found that a combination of inexpensive $\mathrm{NiBr}_{2}(3 \mathrm{~mol} \%), \mathbf{L} 2(4.5 \mathrm{~mol} \%)^{[16]}$ and $\mathrm{Mn}$ as reducing agent in DMF at $\mathrm{rt}$, delivered $3 \mathrm{a}$ in $86 \%$ isolated yield. Importantly, only traces of $\beta$-hydride elimination and homodimerization products were observed in the crude mixtures. Notably, ligand optimization revealed a crucial influence of the substitution pattern on the aromatic ring, with bipyridine ligands lacking ortho substituents (entry 2) or structurally-similar phenanthroline ligands L4-L5 providing inferior results (entries 4 and 5). ${ }^{[17,18]}$ Strikingly, the utilization of L3 had a deleterious 
impact on yield when using 2 a as substrate (entry 3 ), ${ }^{[19]}$ revealing an interesting effect of the substituents located at the ortho position. As shown in entries $6-12$, the use of other solvents, precatalysts, reducing agents or 1a-I/1a-OTs analogues resulted in diminished yields of $3 a^{[20]}$ thus showing the subtleties of our protocol. As expected, control experiments revealed that all of the reaction parameters were critical for success. ${ }^{[15]}$

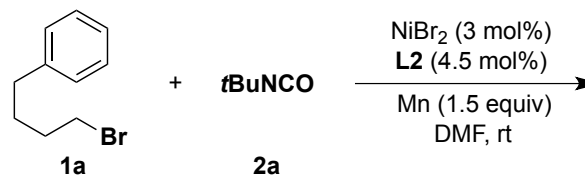

\begin{tabular}{clc}
\hline Entry & Devation from standard conditions & 3a (\%) $)^{[\mathrm{a}],[\mathrm{b}]}$ \\
\hline 1 & none & $95(86)^{[\mathrm{c}]}$ \\
2 & L1 instead of L2 & 39 \\
3 & L3 instead of L2 & 55 \\
4 & L4 instead of L2 & 33 \\
5 & L5 instead of L2 & 30 \\
6 & $\mathrm{NiCl}_{2} \cdot \mathrm{glyme}$ instead of $\mathrm{NiBr}_{2}$ & 80 \\
7 & $\mathrm{Ni}(\mathrm{COD})_{2}$ instead of $\mathrm{NiBr}_{2}$ & 45 \\
8 & MeCN instead of DMF & 0 \\
9 & DMSO instead of DMF & 0 \\
10 & Zn instead of Mn & 0 \\
11 & Using 1a-I instead of 1a & 0 \\
12 & Using 1a-OTs instead of 1a & 40 \\
\hline
\end{tabular}
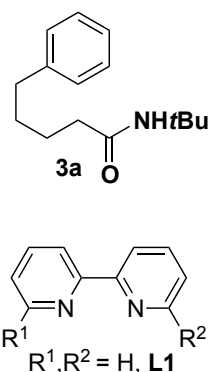

$R^{1}=\mathrm{Me} ; \mathrm{R}^{2}=\mathrm{H}, \mathrm{L} 2$ $\mathrm{R}^{1}, \mathrm{R}^{2}=\mathrm{Me}, \mathrm{L} 3$

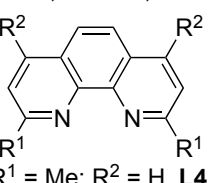

$\mathrm{R}^{1}=\mathrm{Me} ; \mathrm{R}^{2}=\mathrm{H}, \mathbf{L} \mathbf{4}$ $\mathrm{R}^{1}=\mathrm{Me} ; \mathrm{R}^{2}=\mathrm{Ph}, \mathrm{L} 5$

Scheme 2. Optimization of the Ni-catalyzed reductive amidation of $1 \mathrm{a}$ with $\mathbf{2 a}$

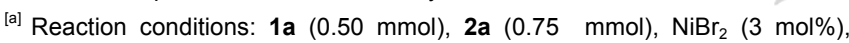
ligand $(4.5 \mathrm{~mol} \%), \mathrm{Mn}(0.75 \mathrm{mmol}), \mathrm{DMF}(1 \mathrm{~mL})$ at $\mathrm{rt}, 16 \mathrm{~h} .{ }^{[\mathrm{b}]} \mathrm{GC}$ yield using $n$-decane as internal standard. ${ }^{[c]}$ Isolated yield. 1a-I = 1-iodo-4-phenylbutane; 1a-OTs = 4-phenylbutyl 4-methylbenzenesulfonate.

Encouraged by these results, we turned our attention to study the preparative scope of our $\mathrm{Ni}$-catalyzed reductive amidation of unactivated alkyl bromides with isocyanates (Scheme 3 ). As shown for 3a-3f, the protocol allowed for the coupling of either aromatic or aliphatic isocyanates with equal ease. Intriguingly, a regime based on L3 was particularly efficient when dealing with aromatic isocyanates. ${ }^{[21,22]}$ At present, we do not have any rational explanation for this behavior. Particularly illustrative was the chemoselectivity profile of the protocol, as substrates containing silyl ethers (3k), acetals (3l), esters (3h, 30, 3q), amides $(\mathbf{3 p})$, nitriles $(\mathbf{3 r})$, heterocycles $(\mathbf{3 q})$ or chlorides $(\mathbf{3} \mathbf{j}, \mathbf{3 n})$ could all be perfectly accommodated. As shown for $\mathbf{3 h}$ and $\mathbf{3 n}$, aryl pivalates and chlorides, substrates commonly employed in $\mathrm{Ni}$-catalyzed cross-electrophile couplings, do not compete with the efficacy of this method. Boronic esters $(3 \mathrm{~m})$ were tolerated as well, leaving an additional handle for further functionalization. Although in lower yields, we found that terminal epoxides could also participate in the targeted reaction (3t). Importantly, the reaction could be easily scaled up, obtaining $3 a$ in similar yields. On the basis of these results, we wondered whether our protocol could accommodate unactivated secondary or tertiary alkyl halides. Despite the higher statistical propensity for $\beta$-hydride elimination pathways and increased steric hindrance around the $\mathrm{C}-\mathrm{Br}$ bond, a host of cyclic and acyclic secondary alkyl bromides could be equally accommodated under otherwise

identical reaction conditions (3t-3x). A noteworthy observation concerns the preferential formation of $\mathbf{3 x}$ from exo-1x, reinforcing the notion that radical species might come into play. ${ }^{[23]}$ The successful preparation of $\mathbf{3 y}$ showcases the generality of our approach as unactivated tertiary alkyl halides have rarely been employed in metal-catalyzed cross-electrophile coupling reactions. ${ }^{[24,25]}$
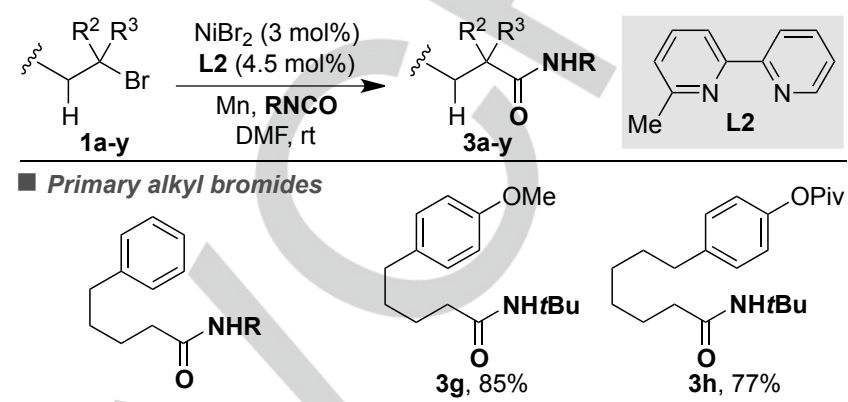

3a, $\mathrm{R}=t \mathrm{Bu}, 86 \%, 74 \%[\mathrm{a}]$

3b, R=Cy, $62 \%[\mathrm{~b}]$

3c, $\mathrm{R}=\mathrm{iPr}, 50 \%[\mathrm{c}]$

3d, $\mathrm{R}=2-\mathrm{OMeC}_{6} \mathrm{H}_{4}, 67 \%$ [d]

3e, $\mathrm{R}=2-\mathrm{PhC}_{6} \mathrm{H}_{4}, 70 \%[\mathrm{~d}]$
3f, $\mathrm{R}=2,4,6-\mathrm{Me}_{3} \mathrm{C}_{6} \mathrm{H}_{2}, 50 \%[\mathrm{~d}]$ $\mathrm{Me}_{\mathbf{3 i}, 76 \%[\mathrm{e}]}^{\mathrm{O}}$

$X \sim \mathrm{NHtBu}$

O

$31, X=\xi-1,76 \%$

$3 \mathrm{~m}, \mathrm{X}=\mathrm{CH}_{2} \mathrm{BP}$ in, $52 \%$<smiles>CCCCNC(=O)CCCCOc1ccc(Cl)cc1</smiles>

3 n, $63 \%$<smiles>CCCCNC(=O)CC(C)CCOC(=O)c1ccoc1</smiles>

$3 q, 76 \%$<smiles>CCCCCC(C)(C)C#N</smiles>

$3 r, 84 \%$

Secondary and tertiary alkyl bromides<smiles>CCCCNC(=O)C1CCCCC1</smiles>

3t, $85 \%[e]$<smiles>CCCCC(C)C(=O)NCCC</smiles>

$3 w, 65 \%$<smiles>CCCCNC(=O)C1CCN(Cc2ccccc2)CC1</smiles>

$3 u, 82 \%$

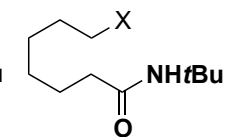

3j, $\mathrm{X}=\mathrm{Cl}, 83 \%$ 3k, $\mathrm{X}=$ OTBDPS, $88 \%$<smiles>[R]C(=O)CCCCCC(=O)NCCC</smiles>

3o, $\mathrm{R}=\mathrm{OEt}, 80 \%$ $3 p, \mathrm{R}=\mathrm{NEt}_{2}, 89 \%$<smiles>CCCCNC(=O)CCCCCCCCCC1CO1</smiles>

3s, $49 \%$<smiles>CCCCNC(=O)C1CCOCC1</smiles>

$3 v, 71 \%$

$3 y, 65 \%[$ [b]<smiles>CCCCNC(=O)C12CC3CC(CC(C3)C1)C2</smiles>

Scheme 3. Scope of alkyl bromides and isocyanates. Reaction conditions: as for Scheme 2, entry 1; Isolated yields, average of at least two independent runs. ${ }^{[a]}$ 1a (4.69 mmol). ${ }^{[b]} \mathrm{NiBr}_{2}$ (10 mol\%), L2 (15 mol\%). ${ }^{[c]}$ [(TMEDA)Ni(otolyl)Cl] (15 mol\%), L2 (30 mol\%). ${ }^{[\mathrm{d}]} \mathrm{NiBr}_{2}$ (10 mol\%), L3 (20 mol\%), RNCO (0.5 mmol). ${ }^{[\mathrm{e}]} \mathrm{NiBr}_{2}$ (5 mol\%), L2 (7.5 mol\%).

A close survey of the literature data reveals that a unified metal-catalyzed strategy for accessing primary, secondary and tertiary amides remains elusive. In a final venture to unlock the full potential of our protocol, we sought to intercept the in situ generated IV upon subsequent addition of a proper electrophile, thus accessing tertiary aliphatic amides in a one-pot fashion 
(Scheme 4, top left). Although counterintuitive at first sight, the preparation of $\mathbf{4 a - 4 d}$ illustrates the feasibility of this approach, constituting a formal cross-coupling reaction of three different electrophiles. On the other hand, primary amides could easily be obtained by deprotection of the tert-butyl group with $\mathrm{Sc}(\mathrm{OTf})_{3}$ (4e). ${ }^{[26]}$ Importantly, such a design principle allowed us to rapidly convert $1 \mathrm{a}$ into $\mathbf{4 f}$, thus constituting a powerful alternative platform for handling flammable and toxic MeNCO in amidation technologies (Scheme 4 , bottom) ${ }^{[27]}$ Taken together, the results in Schemes 3-4 illustrate the prospective impact of our catalytic amidation protocol for accessing a wide variety of amides from simple starting materials in a straightforward manner.

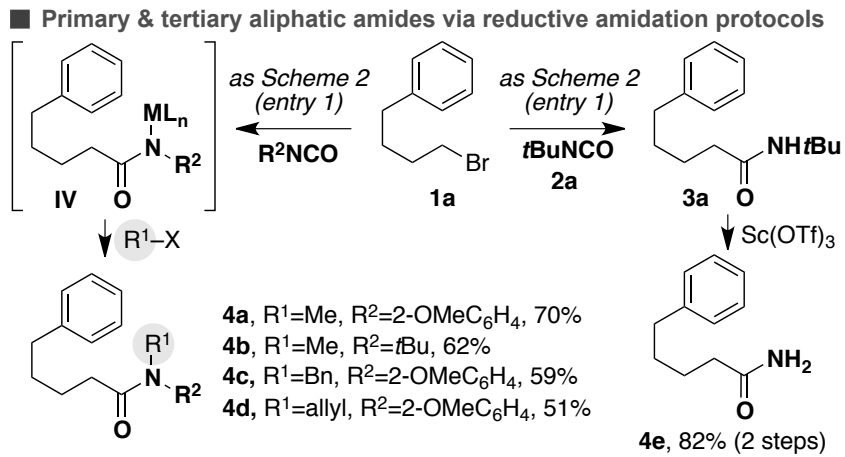

Formal utilization of MeNCO in catalytic reductive amidation<smiles>BrCCCCc1ccccc1</smiles>

$$
\begin{aligned}
& \text { (1) as Scheme } 2 \text { (2a) } \\
& \text { (2) } \mathrm{Mel} \text { (2 equiv) } \\
& \frac{\text { (3) } \mathrm{Cu}(\mathrm{OTf})_{2}(20 \mathrm{~mol} \%)}{60 \% \text { yield }}
\end{aligned}
$$

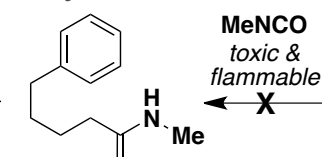

4f 0

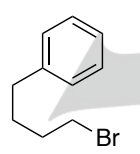

1a
Scheme 4. Iterative $\mathrm{C}-\mathrm{C}$ bond-forming scenarios.

Although a comprehensive mechanistic study should await further investigations, deuterium-labelling experiments were performed to study the stereochemical course of the reaction (Scheme 5, top). Interestingly, we found a statistical mixture of diastereoisomers in $\mathbf{6}$ when exposing $\mathbf{5}$ to our optimized reaction conditions, suggesting the intermediacy of single-electron transfer (SET) processes. ${ }^{[23]}$ In line with this notion, a complete racemization was observed when using (R)-(3-bromobutyl)benzene $(97 \%$ ee) as substrate. We then turned our attention to study the reactivity of the putative $\mathrm{Ni}(0)(\mathbf{L} 3)_{2}(7)$ and $\mathrm{NiBr}_{2}$ (L3) (8) species (Scheme 5, bottom). ${ }^{[28,29]}$ These compounds were easily prepared from either $\mathrm{Ni}(\mathrm{COD})_{2}$ or $\mathrm{NiBr}_{2}$ and were univocally characterized by $\mathrm{X}$-ray crystallography. ${ }^{[15]}$ As expected, both $\mathbf{7}$ and $\mathbf{8}$ were found to be catalytically competent as reaction intermediates, delivering $\mathbf{3 d}$ in comparable yield to that observed in Scheme 3 (57\% yield). ${ }^{[30]}$ More importantly, we found that $\mathbf{3} \mathbf{d}$ could be obtained regardless of whether Mn was present or not with stoichiometric amounts of 7. As expected, $\mathbf{8}$ delivers $\mathbf{3 d}$ with similar yields to those shown for 7 . Although we cannot rigorously rule out other conceivable pathways,$^{[31]}$ we propose a scenario via alkyl-Ni(I) species generated by comproportionation of in situ generated alkyl-Ni(II) intermediates and $\mathrm{Ni}(0)(\mathrm{L})_{2}$ followed by insertion of the isocyanate motif and a final SET mediated by $\mathrm{Mn}^{\left[{ }^{[3,33]}\right.}$

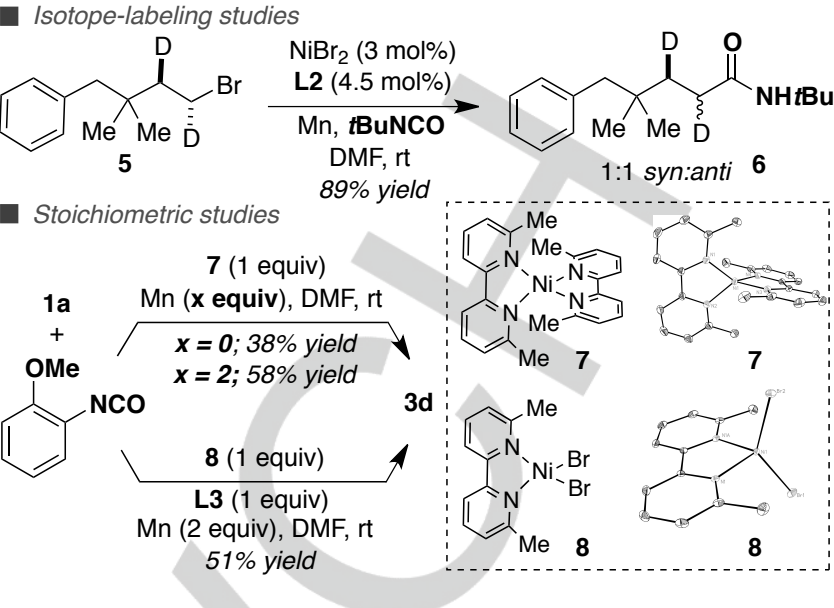

Scheme 5. Preliminary mechanistic studies

In summary, we have described the first Ni-catalyzed reductive amidation of unactivated alkyl halides with isocyanates for accessing primary, secondary or even tertiary amides via iterative techniques. The reaction proceeds under mild conditions, hence minimizing unproductive $\beta$-hydride elimination or dimerization/trimerization events, while accommodating a wide range of substrates with an excellent chemoselectivity profile. Further investigations on the mechanism and the elaboration of an asymmetric version are currently being pursued in our laboratories.

\section{Acknowledgements}

We thank ICIQ, the European Research Council (ERC- 277883), MINECO (CTQ2015-65496-R and Severo Ochoa Excellence Accreditation 2014-2018, SEV-2013-0319), FEDER \& Cellex Foundation for support. Johnson Matthey, Umicore and Nippon Chemical Industrial are acknowledged for a gift of metal and ligand sources. E. Serrano thanks MINECO for a FPI fellowship. We sincerely thank E. Escudero and E. Martin for all X-ray data.

Keywords: unactivated alkyl halides $\cdot$ nickel $•$ reductive coupling - cross-coupling

[1] For selected reviews on catalytic cross-coupling reactions of unactivated alkyl halides via nucleophile/electrophile regimes, see: a) X. Hu, Chem. Sci. 2011, 2, 1867-1886; b) R. Jana, T. P. Pathak, M. S. Sigman, Chem. Rev. 2011, 111, 1417-1492; c) A. C. Frisch, M. Beller, Angew. Chem. 2005, 117, 680-695; Angew. Chem. Int. Ed. 2005, 44, 674-688; d) M. R. Netherton, G. C. Fu, Adv. Synth. Catal. 2004, 346, 1525-1532; e) D. J. Cárdenas, Angew. Chem. 2003, 115, 398-401; Angew. Chem. Int. Ed. 2003, 42, 384-387.

[2] For reviews on cross-electrophile couplings of organic halides, see: a) J. Gu, X. Wang, W. Xue, H. Gong, Org. Chem. Front. 2015, 2, 1411-1421; b) D. J. Weix, Acc. Chem. Res. 2015, 48, 1767-1775; c) T. Moragas, A. Correa, R. Martin, Chem. Eur. J. 2014, 20, 8242-8258; d) C. E. I. Knappke, S. Grupe, D. Gärtner, M. Corpet, C. Gosmini, A. Jacobi von Wangelin, Chem. Eur. J. 2014, 20, 6828-6842.

[3] a) S. Ozaki, Chem. Rev. 1972, 72, 457-496; b) H. Ulrich. Chemistry and Technology of Isocyanates; Wiley: New York, 1996. 
[4] For seminal stoichiometric studies of $\mathrm{Ni}(0)$ complexes with isocyanates: a) H. Hoberg, J. Organomet. Chem. 1988, 358, 507-517; b) H. Hoberg K. Summermann, A. Milchereit, J. Organomet. Chem. 1985, 288, 237248; c) H. Hoberg, E. Hernandez, Angew. Chem. 1985, 97, 987-988 Angew. Chem. Int. Ed. 1985, 24, 961-962; d) J. F. Villa, H. B. Powell, Inorg. Chim. Acta 1979, 32, 199-204.

[5] For selected Ni-catalyzed reactions of isocyanates with coupling partners other than organic halides: a) T. Miura, M. Morimoto, M Murakami, J. Am. Chem. Soc. 2010, 132, 15836-15838; b) T. Ozawa, H. Horie, T. Kurahashi, S. Matsubara, Chem. Commun. 2010, 46, 80558057 ; c) B. R. D'Souza, J. Louie, Org. Lett. 2009, 11, 4168-4171; d) K D. Schleicher, T. F. Jamison, Org. Lett. 2007, 9, 875-878; e) H. A. Duong, M. Cross, J. Louie, J. Am. Chem. Soc. 2004, 126, 11438-11439.

[6] P. Braunstein, D. Nobel, Chem. Rev. 1989, 89, 1927-1945.

[7] a) A. Correa, R. Martin, J. Am. Chem. Soc. 2014, 136, 7253-725;. b) J.C. Hsieh; C.-H. Cheng, Chem. Commun. 2005, 4554-4556.

[8] a) The Amide Linkage: Structural Significance in Chemistry, Biochemistry and Materials Science, (Eds.: A. Greenberg, C. M Breneman, J. F. Liebman), Wiley-Interscience, New York, 2000; b) J. S. Carey, D. Laffan, C. Thomson, M. T. Williams, Org. Biomol. Chem. 2006, 4, 2337-2347.

[9] For selected elegant reviews on amide bond-formation, see: a) V. R. Pattabiraman, J. W. Bode. Nature 2011, 480, 471-479; b) C. L. Allen, J. M. Williams, Chem. Soc. Rev. 2011, 40, 3405-3415; c) R. M. Lanigan, T. D. Sheppard, Eur. J. Org. Chem. 2013, 33, 7453-7465; d) E. Valeur M. Bradley, Chem. Soc. Rev. 2009, 38, 606-631.

[10] For selected examples: a) G. Zhang, B. Gao, H. Huang, Angew. Chem 2015, 127, 7767-7771; Angew. Chem. Int. Ed. 2015, 54, 7657-7661; b) K. Dong, X. Fang, R. Jackstell, G. Laurenczy, Y. Li, M. Beller, J. Am Chem. Soc. 2015, 137, 6053-6058; c) C. Jimenez-Rodriguez, A. A. Nunez-Magro, T. Seidensticker, G. R Eastham, M. R. L Furst, D. J. Cole-Hamilton, Catal. Sci. Technol. 2014, 4, 2332-2339; d) H. Liu, N. Yan, P. J. Dyson, Chem. Commun. 2014, 50, 7848-7851; e) X. Fang, R. Jackstell, M. Beller, Angew. Chem. 2013, 125, 14339-14343; Angew. Chem. Int. Ed. 2013, 52, 14089-14093; f) T. Fukuyama, T. Inouye, I. Ryu, J. Organomet. Chem. 2007, 692, 685-690; g) I. Ryu, K. Nagahara, N. Kambe, N. Sonoda, S. Kreimerman, M. Komatsu, Chem. Commun. 1998, 1953-1954, and references therein.

[11] For selected examples of using organometallic reagents possessing $\beta$ hydrogens, see: a) G. Schäfer, C. Matthey, J. W. Bode, Angew. Chem. 2012, 124, 9307-9310; Angew. Chem. Int. Ed. 2012, 51, 9173-9175 (RMgX); b) V. Pace, L. Castoldi, W. Holzer, Chem. Commun. 2013, 49, 8383-8385 (RLi); c) I. Coldham, S. Dufour, T. F. N. Haxell, J .J. Patel, G. Sanchez-Jimenez, J. Am. Chem. Soc. 2006, 128, 10943-10951 (RLi), and references therein.

[12] Recently, intermolecular catalytic hydrocarbamoylation of non-cyclic alkenes with formamides have been reported for forging aliphatic amide bonds possessing $\beta$-hydrogens. In all cases $\alpha$-branched amides are beyond reach, obtaining exclusive linear selectivity. Examples: a) $\mathrm{T}$. Seidensticker, M. R. L. Furst, R. Frauenlob, J. Vondran, E. Paetzold, U. Kragl, A. J. Vorhold, ChemCatChem 2015, 7, 4085-4090; b) Y. Miyazaki, Y. Yamada, Y. Nakao, T. Hiyama, Chem. Lett. 2012, 41, 298$300 ;$ c) S. Ko, H. Han, S. Chang, Org. Lett. 2003, 5, 2687-2690.

[13] For selected recent examples, see: a) Y. Liu, J. Cornella, R. Martin, J. Am. Chem. Soc. 2014, 136, 11212-11215; b) T. Moragas, J. Cornella, R. Martin, J. Am. Chem. Soc. 2014, 136, 17702-17705; c) X. Wang, Y Liu, R. Martin, J. Am. Chem. Soc. 2015, 137, 6476-6479; d) X. Wang, M. Nakajima, R. Martin, J. Am. Chem. Soc. 2015, 137, 8924-8927.

[14] P. D. Bailey, T. J. Mills, R. Pettecrew, R. A. Price, in Comprehensive Organic Functional Groups Transformation II, Vol. 5 (Eds.: A. R. Katritzky, R. J. K. Taylor), Elsevier: Oxford, 2005, pp. 201-294.

[15] See Supporting information for details.
[16] L2 can be prepared in two steps and in multigram scale following a slightly modified literature procedure: T. Kauffmann, J. König, A. Woltermann, Chem. Ber. 1976, 109, 3864-3868.

[17] For the early use of bipyridine and phenanthroline ligands in crosscoupling reactions of unactivated alkyl halides, see: a) J. Zhou, G. C. Fu, J. Am. Chem. Soc. 2004, 126, 1340-1341; b) D. A. Powell, T. Maki, G. C. Fu, J. Am. Chem. Soc. 2005, 127, 510-511.

[18] While L1 and L5 predominantly lead to homodimerization, significant amounts of $\beta$-hydride elimination and reduction products were observed for a regime based on L4.

[19] Note, however, that L3 turned out to be particularly efficient for aryl isocianates (see Scheme 3).

[20] Full conversion to $\beta$-hydride elimination products was observed for $1 \mathrm{a}-\mathrm{I}$. The observed reactivity of 1a-OTs goes in line with the ability of these substrates to couple with other heterocumulenes (see ref. 13a).

[21] Unlike the utilization of aliphatic isocyanates, equimolar amounts of aromatic isocyanates were critical to prevent the formation of considerable amounts of $\mathrm{N}$-acylureas.

[22] [(TMEDA)Ni(o-tolyl)Cl] turned out to be particularly suited for the coupling of $\mathrm{PrNCO}$, avoiding dimerization or trimerization pathways.

[23] This hypothesis is reinforced by the significant inhibition observed when reacting $\mathbf{1 a}$ with $\mathbf{2 a}$ in the presence of radical scavengers such as TEMPO or BHT. The intermediacy of radical-type intermediates gains credence from the observation that the Ni-catalyzed reductive amidation of 6-bromohex-1-ene results in a linear relationship between acyclic and 5-exo-trig cyclization products at different Ni/L2 loadings.

[24] For remarkable exceptions: a) X. Wang, S. Wang, W. Xue, H. Gong, J. Am. Chem. Soc. 2015, 137, 11562-11565; b) C. Zhao, X. Jia, X. Wang, H. Gong, J. Am. Chem. Soc. 2014, 136, 17645-17651.

[25] Non-caged tertiary alkyl bromides provided traces of products.

[26] A. K. Mahalingam, X. Wu, M. Alterman, Tetrahedron Lett. 2006, 47, 3051-3053.

[27] E. Broughton, Environ. Health. 2005, 4, 6 .

[28] The isolation of $\mathrm{Ni}(0)(\mathbf{L} 2)_{2}$ proved to be particularly recalcitrant. Stoichiometric studies were performed with $\mathrm{Ni}(0)(\mathbf{L} 3)$ and $\mathrm{NiBr}_{2}(\mathbf{L} 3)$, as L3 proved superior for aromatic isocyanates.

[29] CCDC 1481428 (7) and CCDC 1481429 (8) contain the supplementary crystallographic data for this paper and can be obtained free of charge from The Cambridge Crystallographic Data Centre via www.ccdc.cam.ac/uk/data_request/cif

[30] $\beta$-hydride elimination, reduction, homodimerization and the formation of $\mathrm{N}$-acylureas account for the mass balance.

[31] At present, we cannot rule out a significant contribution dealing with $\mathrm{Ni}(\mathrm{I})$ intermediates generated via single-electron transfer reduction mediated by Mn, see: a) E. Duñach, A. P. Esteves, M. J. Medeiros, S. Olivero, New. J. Chem. 2005, 29, 633-636; b) T. Fujihara, Y. Horimoto, T. Mizoe, F. B. Sayyed, Y. Tani, J. Terao, S. Sakaki, Y. Tsuji, Org. Lett. 2014, 16, 4960-4963; c) M. L. Nadal, J. Bosch, J. M. Vila, G. Klein, S Ricart, J. M. Moretó, J. Am. Chem. Soc. 2005, 127, 10476-10477.

[32] For selected comproportionation events en route to $\mathrm{Ni}(\mathrm{I})$ species, see: a) J. Cornella, E. Gómez-Bengoa, R. Martin, J. Am. Chem. Soc. 2013, 135, 1997-2009; b) A. Velian, S. Lin, A. J. M. Miller, M. W. Day, T. Agapie, J. Am. Chem. Soc. 2010, 132, 6296-6297; c) V. B. Phapale, E. Buñuel, M. García-Iglesias, D. J. Cárdenas, Angew. Chem. 2007, 119, 8946-8951; Angew. Chem. Int. Ed. 2007, 46, 8790-8795; d) G. D. Jones, J. L. Martin, C. McFarland, O. R. Allen, R. E. Hall, A. D. Haley, R. J. Brandon, T. Konovalova, P. J. Desrochers, P. Pulay, D. A. Vicic, J. Am. Chem. Soc. 2006, 128, 13175-13183.

[33] $\mathrm{Ni}(\mathrm{I})$ species have been shown to rapidly react with heterocumulenes other than RNCO, see: F. S. Menges, S. M. Craig, N. Tötsch, A Bloomfield, S. Ghosh, H.-J. Krüger, M. A. Johnson, Angew. Chem. 2016, 128,1304-1307; Angew. Chem. Int. Ed. 2016, 55, 1282-1285. 


\section{COMMUNICATION}

Catalytic umpolung amidation of unactivated primary, secondary or tertiary alkyl bromides

$$
\begin{gathered}
\mathrm{H}_{10}^{0}, 2^{\circ} \& 3^{\circ} \\
\text { alkyl bromides }
\end{gathered}
$$

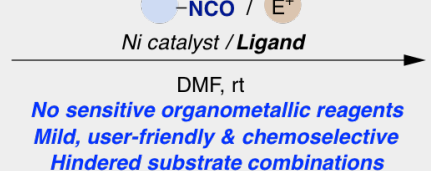

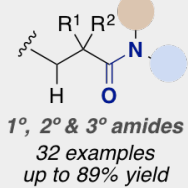

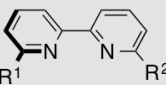

$R^{1}=H, R^{2}=M e, L_{2}$ $R^{1}=M e, R^{2}=M e, L 3$
A versatile $\mathrm{Ni}$-catalyzed reductive amidation of unactivated primary, secondary and tertiary alkyl bromides with isocyanates gives access to a wide range of aliphatic amides. The reaction proceeds under mild conditions and is characterized by an excellent chemoselectivity profile while avoiding the use of stoichiometric and sensitive organometallic reagents.

\section{Eloisa Serrano, Ruben Martin*}

Page No. - Page No.

Ni-Catalyzed Reductive Amidation of

\section{Unactivated Alkyl Bromides}

